\title{
Correspondence
}

\section{Pain on injection of rocuronium: influence of ketamine pretreatment}

To the Editor:

The incidence of pain on injection of rocuronium is high; reports suggest that 50 to $80 \%$ of patients suffer pain that can be distressing. ${ }^{1,2} \mathrm{We}$ assessed the effectiveness of ketamine in minimizing pain on injection of rocuronium in adult patients.

After Institutional Ethics Committee approval and obtaining patients' written informed consent, 150 adult patients ASA physical status I and II who were to undergo elective operations were included in the study. Patients with a history of allergy or convulsions, taking sedatives and analgesic medication, difficult venous access and those requiring rapid sequence induction were excluded. Patients were informed that they would be receiving drugs that may "sting" in their arm at the start of the anesthetic. They were instructed to score pain on a four-point scale: [none $(0)$, mild (1), moderate (2) or severe (3)]. ${ }^{2}$ All patients were interviewed by the investigators six to eight hours after the surgical procedure regarding any weakness or shortness of breath immediately before going to sleep and satisfaction with anesthesia.

On arrival in the operation room, a 20-gauge cannula was placed in the largest vein on the dorsum of the hand without the use of a local anesthetic. Patients were randomly allocated to receive $2 \mathrm{~mL}$ isotonic saline (control group), ketamine $10 \mathrm{mg}$ in $2 \mathrm{~mL}$ saline (K-10 group), or ketamine $20 \mathrm{mg}$ in $2 \mathrm{~mL}$ saline (K20 group) at ambient temperature. Thirty seconds later, an intubating dose of rocuronium $0.6 \mathrm{mg} \cdot \mathrm{kg}^{-1}$ at room temperature was injected and severity of the pain was assessed. Thirty seconds after the administration of rocuronium, propofol was administered intravenously until loss of consciousness and anesthesia proceeded as usual.

The incidence of pain in the control group (78\%) was significantly higher than in the ketamine $10-\mathrm{mg}$ and ketamine $20-\mathrm{mg}$ groups $(40 \%$ and $12 \%$ respectively); $(P<0.05$ and $P<0.01$ respectively $)$. In addition, patients treated with ketamine $20 \mathrm{mg}$ were less likely to suffer moderate or severe pain $(P<0.05$; Table). Five patients in the control group complained of slight muscle weakness before $30 \mathrm{sec}$ and received propofol immediately. Two of these patients could
TABLE Incidence and characteristics of pain on injection of rocuronium

\begin{tabular}{llll}
\hline & Control $(n=50)$ & $K-10(n=50)$ & $K-20(n=50)$ \\
\hline None & 11 & $30^{*}$ & $44^{*} \dagger$ \\
Mild & 12 & 9 & 3 \\
Moderate & 17 & 9 & $2^{*}$ \\
Severe & 9 & 2 & $1^{*}$ \\
\hline
\end{tabular}

${ }^{*} P<0.05$ as compared to control; $\dagger P<0.05 \mathrm{~K}-20$ compared with K-10 (Chi-square). Results are expressed as number of patients who responded.

recall the induction sequence. However, none of these patients expressed dissatisfaction. Our results indicate that ketamine pretreatment, preferably in a dose of 20 $\mathrm{mg}$, significantly reduces the pain associated with the injection of rocuronium in adults.

Pretreatment with ketamine has been found to alleviate pain on injection of propofol..$^{3,4}$ The site of action of ketamine in reducing pain may be either central or peripheral. Ketamine acts on a multitude of receptors. It is a non-competitive N-methyl-D-aspartic acid receptor antagonist and opioid $\mu$ receptor agonist in the central nervous system and vascular endothelium. These actions of ketamine may have attenuated the pain caused by rocuronium. ${ }^{5}$ Ketamine has also been shown to have a local analgesic action when administered for $i v$ regional analgesia. ${ }^{5}$ It is possible that the reduction in pain injection was the result of a local peripheral action.

Rajesh Mahajan MD

Yatendra Kumar Batra MD MNAMS

Sushil Kumar MD

Chandigarh, India

\section{References}

1 Cheong KF, Wong WH. Pain on injection of rocuronium: influence of two doses of lidocaine pretreatment. Br J Anaesth 2000; 84: 106-7.

2 Turan A, Memis D, Karamanlioglu B, Sut N, Pamukcu $Z$. The prevention of pain from injection of rocuronium by magnesium sulphate, lignocaine, sodium bicarbonate and alfentanil. Anaesth Intensive Care 2003; 31: 277-81.

3 Tan CH, Onsiong MK, Kua $S W$. The effect of ketamine pretreatment on propofol injection pain in 100 
women. Anaesthesia 1998; 53: 302-5.

4 Suzuki S, Masamune T, Nonaka A, Kumazawa T. Pretreatment with ketamine reduces incidence and severity of pain on propofol injection (Japanese). Masui 2002; 51: 140-3.

5 Hirota K, Lambert DG. ketamine: its mechanism(s) of action and unusual clinical uses. Br J Anaesth 1996; 77: $441-4$.

\section{Continuous extrapleural infusion of ropivacaine in children: is it safe?}

To the Editor:

In contrast to bupivacaine, ropivacaine has not yet been shown to be suitable in the clinical context of continuous intercostal nerve blockade using an extrapleural catheter in children and young infants. ${ }^{1,2}$ After approval of the hospital's Ethical Committee and obtaining parental consent, the pharmacokinetics of an extrapleural bolus of $0.5 \mathrm{~mL} \cdot \mathrm{kg}^{-1}$ ropivacaine $0.2 \%$ followed by a continuous extrapleural infusion at two different rates $\left(0.2 \mathrm{~mL} \cdot \mathrm{kg}^{-1} \cdot \mathrm{hr}^{-1}\right.$ and 0.3 $\mathrm{mL} \cdot \mathrm{kg}^{-1} \cdot \mathrm{hr}^{-1}$, resp.) for $48 \mathrm{hr}$ were evaluated in two children undergoing cardiac surgery via a lateral thoracotomy (patient 1: male, four years old; patient 2: female, six years old). Anesthesia was performed according to our standard protocol and at the end of the operation an extrapleural catheter (20-gauge, multi-orifice, SIMS Portex Ltd., Hythe, UK) was placed as described earlier. ${ }^{3}$ The bolus of ropivacaine $0.2 \%$ was administered when the patients recovered from anesthesia (adequate reactions to verbal command) and the infusion was maintained for $48 \mathrm{hr}$. Total plasma concentrations of ropivacaine and plasma concentration of $\alpha_{1}$-acid glycoprotein were assessed at the hours $\mathrm{t}=1 / 6,1 / 3,0.5,1,3,6,18,30,48,50$, 52 and 54 . Total ropivacaine plasma concentration showed a first peak $30 \mathrm{~min}$ after the initial bolus. Its highest value was measured at the end of the continuous infusion (Figure) and exceeded the limit of 2.2 $\mathrm{mg} \cdot \mathrm{L}^{-1}$ that is accepted to be safe in terms of toxicity as described by Knudsen et al. ${ }^{4}$ The measured concentrations of $\alpha_{1}$-acid glycoprotein remained within the normal range. The capacity of $\alpha_{1}$-acid glycoprotein to buffer the free fraction of ropivacaine which, mainly, is responsible for toxic reactions in the context of a continuous infusion of local anesthetics was, therefore, not increasing. Thus, we may not assume a subsequent decrease in the unbound fraction of ropivacaine. Clinically, no pathological findings in terms of toxicity were found.

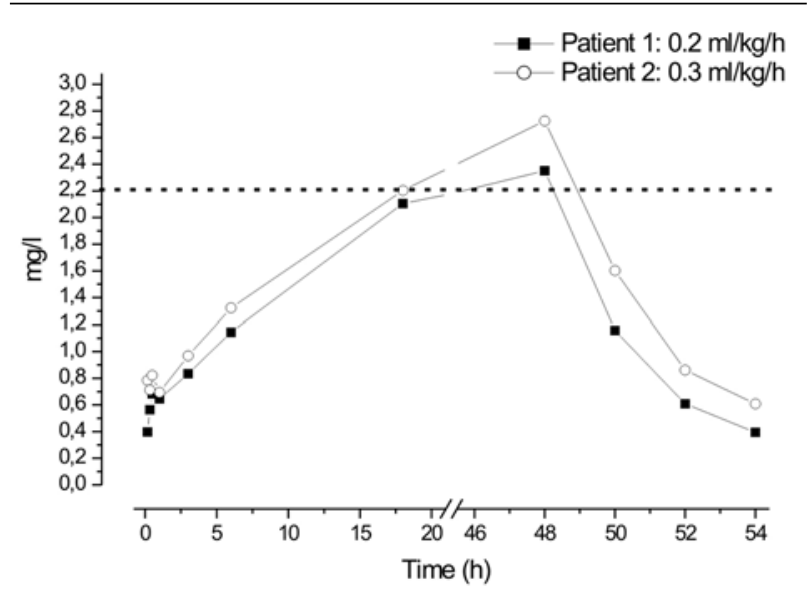

FIGURE Evolution of venous total ropivacaine concentrations. Hours $=$ time in hours after administration of the bolus of ropivacaine. The continuous extrapleural infusion of ropivacaine $0.2 \%$ was stopped at $48 \mathrm{hr}$.

Our preliminary results suggest that intercostal nerve block with an initial bolus of $0.5 \mathrm{~mL} \cdot \mathrm{kg}^{-1}$, followed by a continuous infusion through an extrapleural catheter of $2 \mathrm{mg} \cdot \mathrm{mL}^{-1}$ ropivacaine at $0.2 \mathrm{~mL} \cdot \mathrm{hr}^{-1}$ and 0.3 $\mathrm{mL} \cdot \mathrm{hr}^{-1}$ over $48 \mathrm{hr}$ is at the edge of being considered a safe technique for analgesia after lateral thoracotomy. More investigations - also in terms of pharmacodynamics - are needed to determine the optimal rate and concentration of ropivacaine administered through an extrapleural catheter in children.

Konrad Maurer MD

Katharina M. Rentsch PhD

Alexander Dullenkopf MD

René Prêtre MD

Edith R. Schmid MD

Zurich, Switzerland

Support was provided solely from departmental sources.

\section{References}

1 Downs CS, Cooper MG. Continuous extrapleural intercostal nerve block for post thoracotomy analgesia in children. Anaesth Intensive Care 1997; 25: 390-7.

2 Karmakar MK, Booker PD, Franks R, Pozzi M. Continuous extrapleural paravertebral infusion of bupivacaine for post-thoracotomy analgesia in young infants. Br J Anaesth 1996; 76: 811-5.

3 Sabanathan S, Eng J, Mearns AJ. Alterations in respiratory mechanics following thoracotomy. J R Coll Surg Edinb 1990; 35: 144-50. 